\title{
Extraction of rubidium and cesium from brine solutions using a room tem- perature ionic liquid system containing 18-crown-6
}

\author{
Dongfang Huang ${ }^{1,2,3}$, Hong Zheng ${ }^{4 *}$, Zeyu Liu ${ }^{1,2,3}$, Amin Bao ${ }^{1,2,3}$, Bo Li ${ }^{1,2}$ \\ ${ }^{1}$ Chinese Academy of Sciences, Key Laboratory of Comprehensive and Highly Efficient Utilization of Salt Lake Resources, \\ Qinghai Institute of Salt Lakes, 810008 Xining, China \\ ${ }^{2}$ Qinghai Engineering and Technology Research Center of Comprehensive Utilization of Salt Lake Resources, 810008 \\ Xining, China \\ ${ }^{3}$ University of Chinese Academy of Sciences, 100049 Beijing, China \\ ${ }^{4}$ Department of Chemistry, Chongqing Normal University, Chongqing, 400047, China \\ "Corresponding author: e-mail: 348931432@qq.com
}

\begin{abstract}
Application of 1-butyl-3-metyhlimidazaolium hexafluorophosphate $\left([\mathrm{C} 4 \mathrm{mim}]\left[\mathrm{PF}_{6}\right]\right)$, in the extraction of rubidium and cesium from brine solutions using 1,4,7,10,13,16-hexaoxacyclooctadecane (18C6) as extractant was investigated. Parameters that affect the extraction including $\mathrm{pH}$ of aqueous phase, equilibration time, dosage of the ionic liquid, phase ratio, concentration of $18 \mathrm{C} 6$ were studied. Under the optimal conditions, the single extraction efficiency of rubidium ions and cesium ions were up $84.11 \%$ and $94.99 \%$, respectively. The stripping of alkali metal ions from the loaded organic phase with different stripping agents and concentrations were also investigated. The initial value of the $\mathrm{K} / \mathrm{Cs}$ and $\mathrm{K} / \mathrm{Rb}$ ratios were 93.0 and 104.3, respectively, which have dropped $91.21 \%$ and $88.01 \%$, respectively, after the extraction and stripping experiments. It was taken a big step in the separation and enrichment of cesium (rubidium) ion and potassium ion. The extraction mechanism was revealed most likely to be a cation exchange mode in this system.
\end{abstract}

Keywords: Rubidium; Cesium; Ionic liquid; 18-crown-6; Solvent extraction.

\section{INTRODUCTION}

Rubidium and cesium are important rare metals which are playing increasingly important roles in the fields of metal-ion catalysts, new materials, national defense, fiber optic telecommunication systems and new energy ${ }^{\mathbf{1}-3}$. Currently, large amounts of rubidium and cesium dissolved in salt lakes are not fully utilized. Because potassium ion and other alkali ions coexist in salt lake brine which have similar physical and chemical properties to those of rubidium and cesium, the separation and purification of rubidium ions and cesium ions is difficult ${ }^{4-5}$. The methods of separating rubidium ions and cesium ions from salt lake brine mainly including precipitation, ion exchange, and extraction. Among them, liquid-liquid extraction is an economical, efficient method for the separation of $\mathrm{Rb}^{+}$and $\mathrm{Cs}^{+}$especially for the brine sources of a high $\mathrm{K} / \mathrm{Rb}(\mathrm{Cs})$ ratio $^{6-7}$. Liu et al. ${ }^{8}$ studied the extraction of $\mathrm{Rb}^{+}$and $\mathrm{Cs}^{+}$with 4-tert-butyl-2-( $\alpha$-methylbenzyl)phenol (t-BAMBP) in sulfonated kerosene, after 5-stage counter current extraction, the final extraction yields of $\mathrm{Rb}^{+}$and $\mathrm{Cs}^{+}$reached $95.04 \%$ and $99.80 \%$, respectively, but the scrubbing yield of rubidium was only about $10.5 \%$ when the extraction solvent was washed 3 times with $\mathrm{NaOH}$. Moreover, the strong alkaline condition in the system may result in sever corrosion to the equipment. Ali et al. ${ }^{9}$ investigated the dual mode of extraction for $\mathrm{Cs}^{+}$ and $\mathrm{Na}^{+}$ions with dicyclohexano-18-crown-6 and bis(2propyloxy)-calix[4] crown-6, the results show unusually high selectivity of the $\mathrm{Cs}^{+}$over the $\mathrm{Na}^{+}$with bis(2propyloxy)calix[4]crown-6 compared to dicyclohexano18-crown-6. Wang et al. ${ }^{\mathbf{1 0}}$ reported extraction of cesium ions with $\mathrm{iPr}-\mathrm{C}[4] \mathrm{C}-6$ in n-octanol from simulated high level liquid waste (HLLW). The results indicates that the complex has $1: 1\left[\mathrm{Cs}^{+} . \mathrm{PPr}-\mathrm{C}[4] \mathrm{C}-6\right] \mathrm{Cs}^{+}$to ligand and $0.025 \mathrm{~mol} / \mathrm{L}$ iPr-C[4]C-6/noctanol is an effective process for removing Cs from HLLW.
Up to date, not much work have been reported on the extraction of rubidium ions and cesium ions from brine solutions. It is desired to establish a safe and environmental friendly extraction system to extract rubidium ions and cesium ions.

Room temperature ionic liquids (RTILs) are composed of cations and anions, of which the melting points are generally below $373 \mathrm{~K}^{\mathbf{1 1}}$. Because of their characteristics such as low melting temperature, low volatility, low phase disengagement time and benign nature, RTILs are considered to be promising green alternatives to the conventional solvents ${ }^{12}$, 13 . Furthermore, RTILs can dissolve a wide spectrum of inorganic, organic and organometallic compounds, the low volatility of RTILs will avoid safety and environmental problems, as is a trouble case in traditional organic solvents. In recent years, RTILs are received increasing attention for their unique characteristics, which are playing an important role in separation, catalysis, synthesis and material sciences ${ }^{14-17}$. Shi et al. ${ }^{18}$ reported a highly efficient solvent system using tributyl phosphate in $\left[\mathrm{C}_{\mathrm{n}} \operatorname{mim}\right]\left[\mathrm{PF}_{6}\right](\mathrm{n}=4,6$, 8 ) for lithium ion extraction from salt lake brine. The extraction systems used crown ether as the extractants and ILs as the diluents have been aroused the great interests among inveatigators ${ }^{19}$. Luo et al. ${ }^{20}$ investigated the solvent extraction of cesium ions from aqueous solution using calix[4]arene-bis(tert-octylbenzo-crown-6) (BOBCalixC6) as an extractant in ionic liquids $\left(\left[\mathrm{C}_{4} \mathrm{mim}\right]\right.$ $\left.\left.\left[\mathrm{NTf}_{2}\right]\right]\right)$, the results indicates the distribution of cesium at various concentrations of BOBCalixC6 in ions liquid used here are high and have a good selectivity in given concentration of ions liquid $(13.6 \mathrm{mmol} / \mathrm{L})$. Dai et al. ${ }^{21}$ used crown ether/RTILs systems for the extractions of strontium, it revealed that the distribution ratio of $\mathrm{Sr}^{2+}$ from the ionic liquid extraction system was significantly higher than that of the traditional organic solvent system, 
which was up to 4 orders of magnitude. Visser et al. ${ }^{22}$ analyzed the extraction mechanism of $\mathrm{UO}_{2}{ }^{2+}$ based on $\left[\mathrm{C}_{4} \mathrm{mim}\right]\left[\mathrm{PF}_{6}\right] / \mathrm{CMPO}$ system. Finding that the extraction mechanism of $\mathrm{UO}_{2}{ }^{2+}$ in dodecane is a neutral mechanism, but ions exchange in ions liquid.

In the present work, the extraction of rubidium and cesium from brine solutions is investigated using 1,4,7,10,13,16-hexaoxacyclooctadecane (18C6) as extractant and 1,2-dichloroethane as diluent in the room temperature ionic liquid, 1-butyl-3-metyhlimidazaolium hexafluorophosphate $\left(\left[\mathrm{C}_{4} \mathrm{mim}\right]\left[\mathrm{PF}_{6}\right]\right)$. To evaluate the potential use of RTILs to replace traditional volatile organic compounds (VOCs) in liquid/liquid extraction of rubidium and cesium, the extractions of metal ions with VOCs and ionic liquid were compared. The equipment corrosion and the environmental pollution have been avoided in this new extraction system. The $18 \mathrm{C} 6 /\left[\mathrm{C}_{4} \mathrm{mim}\right]$ $\left[\mathrm{PF}_{6}\right]$ extraction system is discussed in detail with the effects of various parameters such as $\mathrm{pH}$ of aqueous phase, dosage of the ionic liquid, phase ratio, concentration of 18C6. The stripping of alkali metal ions from the loaded organic phase with different stripping agents and concentrations is also investigated. Furthermore, a cation exchange mode extraction mechanism is proposed.

\section{MATERIAL AND METHODS}

\section{Material and apparatus}

1,4,7,10,13,16-hexaoxacyclooctadecane (18C6) (AR, $>95 \%$ ) was supplied by Energy Chemical Reagent Co., Ltd; 1,2-dichloroethane (AR) was purchased from Tianjin Kermel Reagent Co., Ltd; room temperature ionic liquid, viz. 1-butyl-3-methylimidazolium hexafluorophosphate $\left(\left[\mathrm{C}_{4} \mathrm{mim}\right]\left[\mathrm{PF}_{6}\right]\right)$, 1-hexyl-3-methylimidazolium hexafluorophosphate $\left(\left[\mathrm{C}_{6} \mathrm{mim}\right]\left[\mathrm{PF}_{6}\right]\right), 1$-octyl-3-methylimidazolium hexafluorophosphate $\left(\left[\mathrm{C}_{8} \mathrm{mim}\right]\left[\mathrm{PF}_{6}\right]\right)$ with purity $>99 \%$ were procured from Shanghai Institute of Organic Chemistry, CAS. The ions concentration in brine solutions are as follows: $\mathrm{Rb}^{+}(101.3 \mathrm{mg} / \mathrm{L})+\mathrm{Cs}^{+}(113.7$ $\mathrm{mg} / \mathrm{L})+\mathrm{K}^{+}(10.57 \mathrm{~g} / \mathrm{L}) \cdot \mathrm{pH}$ meter (pHS-3C), Shanghai LeiCi Scientific Instrument Co., Ltd; thermostatic water bath oscillators (SHA-B, The Jintan city, Jiangsu province Youlian Instrument Research Institute.); atomic absorption spectrometer (GBC 908, GBC Scientific Equipment Pty., Ltd.); inductively coupled plasma mass spectrometry (ELAN DRC-e, Perkin Elmer Company, USA); UV-visible spectroscopic studies were carried out using a Shimadzu (Kyoto, Japan) UV-2600 single beam spectrophotometer using quartz cells and suitable reference solutions.

\section{Extraction experiments}

According to the required concentration, dissolve a certain amount of $18 \mathrm{C} 6$ and $\left[\mathrm{C}_{n} \operatorname{mim}\right]\left[\mathrm{PF}_{6}\right](\mathrm{n}=4,6,8)$ in 1,2-dichloroethane (or chloroform, ethyl acetate, xylene), all the extraction studies were carried out at 291K, and without adjusted $\mathrm{pH}$ except the experiments of investigated the effect of aqueous phase initial $\mathrm{pH}$. Extractions were performed by shaking of the extraction mixture for 15 min. Separation of the organic phases and aqueous phase was assisted by centrifugation. The aqueous phase was properly diluted after phase disengagement. Then, the concentration of $\mathrm{Rb}^{+}\left(\mathrm{Cs}^{+}\right)$was measured using an AAS and $\mathrm{K}^{+}$was measured by ICP-MS. The concentration of metal ions in organic phase was calculated as the difference between the initial and final concentration of ions in the aqueous phase. For stripping experiments, the loaded organic phase was scrubbed by ammonium nitrate solution (or hydrochloric acid, sulfuric acid, nitric acid, ammonium chloride), which was performed under shaking in separating funnel for $10 \mathrm{~min}$. In the following step, the organic phase was scrubbed with deionized water a few times until to neutral. Then the organic phase was dried for reuse in the next cycle.

The distribution ratio $(D)$ is the ratio of the concentration of the metal ion $\left(\mathrm{M}^{+}\right)$in the organic phase to the concentration of the metal ion in the aqueous phase, at equilibrium:

$D=\frac{C_{M^{+}, o r g}}{C_{M^{+}, a q}}=\frac{C_{i}-C_{f}}{C_{f}} \times \frac{V_{a q}}{V_{o r g}}$

Where $C_{\mathrm{i}}$ and $C_{\mathrm{f}}(\mathrm{mg} / \mathrm{L})$ are the initial and final equilibrated concentrations of metal ions in the aqueous phase, respectively. $V_{\mathrm{aq}}(\mathrm{mL})$ and $V_{\text {org }}(\mathrm{mL})$ represent the volume of the aqueous phase and organic phase, respectively. The extraction efficiency $(E)$ is defined as the amount of metal extracted to the organic phase over the total amount of metal in both phases and is given by the following expression:

$E(\%)=\frac{\left(C_{i}-C_{f}\right) \times V_{a q}}{C_{i} \times V_{a q}} \times 100$

In order to show to the difficulty of the separation between two different ions, need to compute both separation factor $(\beta)$, such as $A, B$ two ions separation factor can be calculated by the next type:

$\beta=\frac{D_{A}}{D_{B}}$

Where $D_{\mathrm{A}}$ and $D_{\mathrm{B}}$ are the distribution ratio of $A$ and $B$, respectively. The more $\beta$ value differs from 1 , the better the effect of separation $\mathrm{A}$ and $\mathrm{B}$.

\section{RESULTS AND DISCUSSION}

\section{Effect of $18 \mathrm{C6}$ in various solvent}

Experiments were conducted to study the extraction of $\mathrm{Rb}^{+}$and $\mathrm{Cs}^{+}$using 1,4,7,10,13,16-hexaoxacyclooctadecane (18C6) in various solvents like 1,2-dichloroethane, chloroform, ethyl acetate, xylene and room temperature ionic liquid, 1-butyl-3-methylimidazolium hexafluorophosphate $\left(\left[\mathrm{C}_{4} \mathrm{mim}\right]\left[\mathrm{PF}_{6}\right]\right)$. The diluent of the last one was composed of $20 \%$ IL and $80 \%$ 1,2-dichloroethane. The extraction results are presented in Table 1 . The maximum extraction percentage and distribution ratio of $\mathrm{Rb}^{+}$and $\mathrm{Cs}^{+}$using 18C6 in ionic liquid was found. Based on the maximum extraction percentage of $\mathrm{Rb}^{+}$ and $\mathrm{Cs}^{+}$from brine solutions using $18 \mathrm{C} 6$ dissolved in different solvents, the following order was obtained: ionic liquid $>1,2$-dichloroethane $>$ chloroform $>$ ethyl acetate $>$ xylol. The results show vast opportunities in separation applications for ionic liquids with 18C6 which are consistent with the literature ${ }^{23}$. 


\section{Effect of the aqueous phase initial $\mathbf{p H}$}

The solution acidity was an important factor and could not be ignored for many extraction systems. It was therefore necessary to study the effect of the $\mathrm{pH}$ value of the aqueous phase on the extraction of $\mathrm{Rb}^{+}$ and $\mathrm{Cs}^{+}$using $18 \mathrm{C} 6$ in $\left[\mathrm{C}_{4} \mathrm{mim}\right]\left[\mathrm{PF}_{6}\right]$. The $\mathrm{pH}$ value of the aqueous phase was adjusted by the hydrochloric acid and sodium hydroxide. In this work, the $\mathrm{pH}$ value ranged from 1 to 14 .

As the results shown in Figure 1, the extraction of $\mathrm{Rb}^{+}$ and $\mathrm{Cs}^{+}$was independent of the $\mathrm{pH}$ value range from $3-13$, which resulted in no significant variation in $\mathrm{Rb}^{+}$ and $\mathrm{Cs}^{+}$extraction efficiency. But the extraction efficiency was lower in strong acid environment, of which the value of $\mathrm{pH}$ was 1 . The probable reason was the associated reaction competition between hydrogen ions and other metal ions was not very strong. Besides that, Figure 1 shows that the extraction efficiency of $\mathrm{Rb}^{+}$and $\mathrm{Cs}^{+}$was much greater than that of the $\mathrm{K}^{+}$, which indicated high selectivity to $\mathrm{Cs}^{+}$and $\mathrm{Rb}^{+}$in this system. Since the $\mathrm{pH}$ of the brine solutions is 9.32 , the brine solutions can be used for extracting directly without adjusting the $\mathrm{pH}$ value in this extraction system.

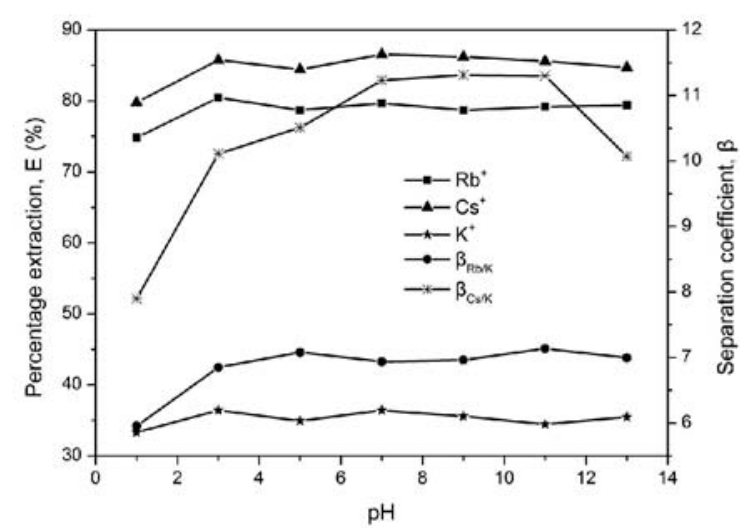

Figure 1. Effects of aqueous phase $\mathrm{pH}$ on extraction efficiencies of metal ions (the ratio of 1,2-dichloroethane/ IL at $8 / 2(\mathrm{~V} / \mathrm{V})$, concentration of $18 \mathrm{C} 6$ is $0.5 \mathrm{~mol} / \mathrm{L}$, $\mathrm{O} / \mathrm{A}$ of $1: 1$, equilibration time of $15 \mathrm{~min}$ )

\section{Effect of the equilibration time}

The length of the extraction equilibrium time and the difficulty of the separation of the extraction process are directly related to the feasibility and efficiency of the extraction process. The effect of the equilibration time was experimentally studied in the range of $0-20 \mathrm{~min}$ and the result was shown in Figure 2. As see in the following graph, the extraction efficiency of $\mathrm{Rb}^{+}$and $\mathrm{Cs}^{+}$were low when the equilibration time was $0.5 \mathrm{~min}$, and the extraction efficiency tended to be stable when it was more than $5 \mathrm{~min}$. Then, it took around nearly $10 \mathrm{~min}$ at a minimum to obtain equilibrium which had the maximum extraction efficiency, but the maximum separation factor of $\beta_{\mathrm{Rb} / \mathrm{K}}$ and $\beta_{\mathrm{Cs} / \mathrm{K}}$ were appeared at 15 min. In view of the fast attainment of equilibrium and higher separation factor values, the equilibration time of 15 min was chosen for subsequent studies.

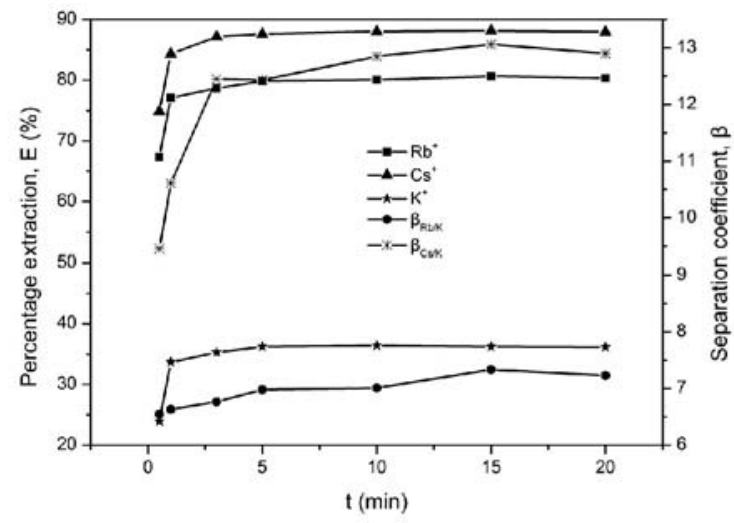

Figure 2. Effects of the equilibration time on the extraction efficiencies of metal ions (the ratio of 1,2-dichloroethane/IL at $8 / 2(\mathrm{~V} / \mathrm{V})$, concentration of $18 \mathrm{C} 6$ is 0.5 $\mathrm{mol} / \mathrm{L}, \mathrm{O} / \mathrm{A}$ at $1: 1$, and unadjusted $\mathrm{pH}$ )

\section{Effect of the concentration of $18 \mathrm{C} 6$ in organic phase}

The extraction behaviors of metal ions by the 18C6/ $\left[\mathrm{C}_{4} \mathrm{mim}\right]\left[\mathrm{PF}_{6}\right]$ system with various concentrations of $18 \mathrm{C} 6$ in the organic phase were studied. The 18C6's concentration was varied over the range $0.1-0.5 \mathrm{~mol} / \mathrm{L}$. As show in Figure 3, with the increase of the concentration of extractant, the extraction rate of metal ions is increasing, and the growth rate of $\mathrm{Rb}^{+}$and $\mathrm{Cs}^{+}$extraction rate is much higher than that of $\mathrm{K}^{+}$, which can also be seen from the change of $\beta_{\mathrm{Rb} / \mathrm{K}}$ and $\beta_{\mathrm{Cs} / \mathrm{K}}$. When the concentration of $18 \mathrm{C} 6$ in the organic phase is $0.5 \mathrm{~mol} / \mathrm{L}$, the extraction rate of $\mathrm{Rb}^{+}$and $\mathrm{Cs}^{+}$reached as high as $78.48 \%$ and $89.18 \%$, respectively. However, it becomes very difficult to further dissolve the extractant in the solvent due to the limitation of solubility. $0.5 \mathrm{~mol} / \mathrm{L}$ is the solubility maxima for 18C6 in the solvent (20\% IL $+80 \%$ 1,2-dichloroethane). So we did not continue to do a high concentration of extraction experiments, and selected $0.5 \mathrm{~mol} / \mathrm{L}$ as the concentration of extractant.

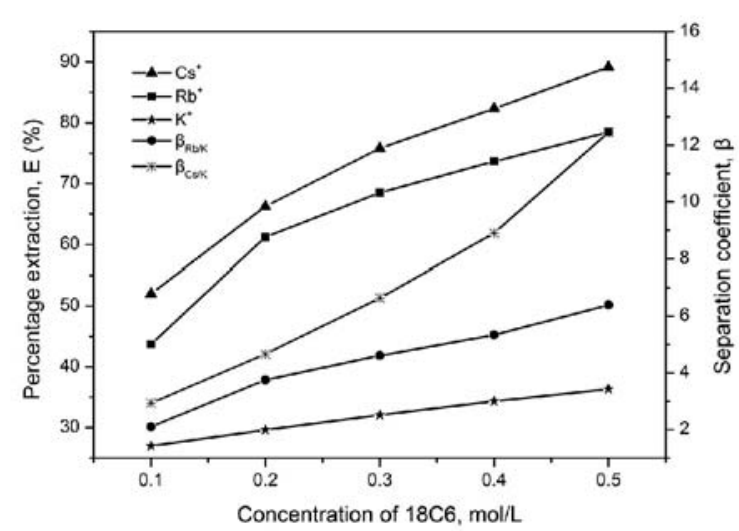

Figure 3. Effects of the 18C6's concentration on extraction efficiencies of metal ions (the ratio of 1,2-dichloroethane/IL at $8 / 2(\mathrm{~V} / \mathrm{V}), \mathrm{O} / \mathrm{A}$ of $1: 1$, equilibration time of $15 \mathrm{~min}$ and unadjusted $\mathrm{pH}$ ) 


\section{Effect of RTILs in $18 \mathrm{C} 6$}

The ionic liquid played a key role in the extraction process, as the experimental results showed in Table 1. So the volume of ionic liquid would affect the extraction efficiency of $\mathrm{Rb}^{+}$and $\mathrm{Cs}^{+}$directly. In this work, the effect of addition of ionic liquid $\left[\mathrm{C}_{4} \mathrm{mim}\right]\left[\mathrm{PF}_{6}\right]$ in 1,2-dichloroethane was experimentally studied in the range of $0-40 \%(\mathrm{v} / \mathrm{v})$ and the results were shown in Figure 4. It is observed from Figure 4 that the separation factor of $\beta_{R b / K}$ and $\beta_{C S I K}$ initially increased with an increase in ionic liquid concentration and it reached the maximum when the volume fraction of ionic liquid is $20 \%$. Further increase of ionic liquid vol.\% may result in the decrease in the separation factor values. The reason is the extraction efficiency of $\mathrm{K}^{+}$increased more than $\mathrm{Rb}^{+}$and $\mathrm{Cs}^{+}$ when the volume fraction of ionic liquid is greater than $20 \%$. So the ionic liquid volume of $20 \%$ by total organic phase volume is chosen for further studies.

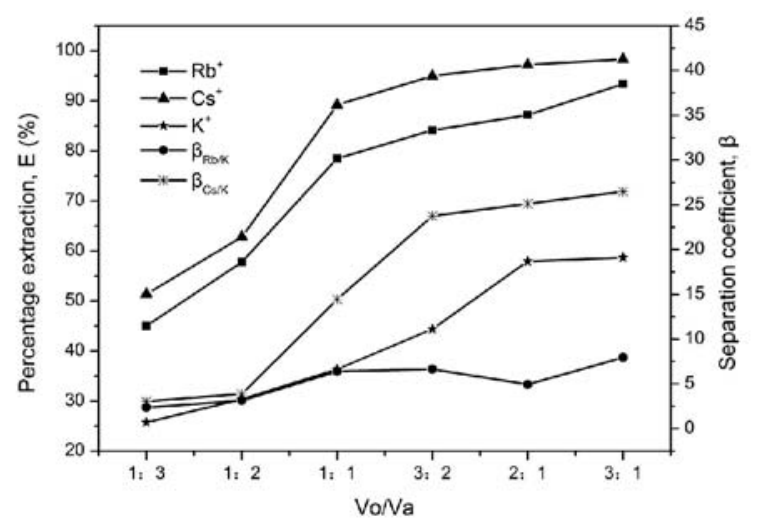

Figure 5. Effects of phase ratio on the extraction efficiencies of metal ions (the ratio of 1,2-dichloroethane/IL at $8 / 2(\mathrm{~V} / \mathrm{V})$, concentration of $18 \mathrm{C} 6$ is $0.5 \mathrm{~mol} / \mathrm{L}$, the equilibration time of $15 \mathrm{~min}$, and unadjusted $\mathrm{pH}$ )

Table 1. Effect of different solvents on extraction efficiency of alkali metal ions (the concentration of $18 \mathrm{C} 6$ is $0.5 \mathrm{~mol} / \mathrm{L}$, O/A of $1: 1$, equilibration time of $15 \mathrm{~min}$ )

\begin{tabular}{|l|c|c|c|c|c|c|c|c|}
\hline Solvent & $\begin{array}{c}\mathrm{E} \% \\
\left(\mathrm{Rb}^{+}\right)\end{array}$ & $\begin{array}{c}\mathrm{E} \% \\
\left(\mathrm{Cs}^{+}\right)\end{array}$ & $\begin{array}{c}\mathrm{E} \% \\
\left(\mathrm{~K}^{+}\right)\end{array}$ & $\mathrm{D}_{\mathrm{Rb}}$ & $\mathrm{D}_{\mathrm{Cs}}$ & $\mathrm{D}_{\mathrm{K}}$ & $\beta_{\mathrm{Rb} / \mathrm{K}}$ & $\beta_{\mathrm{Cs} / \mathrm{K}}$ \\
\hline Xykne & 35.64 & 45.65 & 14.92 & 0.554 & 0.840 & 0.172 & 3.218 & 5.629 \\
\hline Ethyl acetate & 37.51 & 48.99 & 19.45 & 0.600 & 0.960 & 0.238 & 2.523 & 4.937 \\
\hline Chloroform & 38.20 & 43.71 & 17.19 & 0.618 & 0.777 & 0.204 & 3.029 & 4.519 \\
\hline 1,2-dichloroethane & 38.30 & 49.25 & 19.07 & 0.621 & 0.971 & 0.232 & 2.673 & 5.088 \\
\hline $\begin{array}{l}20 \%\left[\mathrm{C}_{4} \text { mim][PF}\right. \\
80 \% \text { 1,2-dichloroethane }\end{array}$ & 78.48 & 88.04 & 36.54 & 3.647 & 7.360 & 0.571 & 6.382 & 12.88 \\
\hline
\end{tabular}

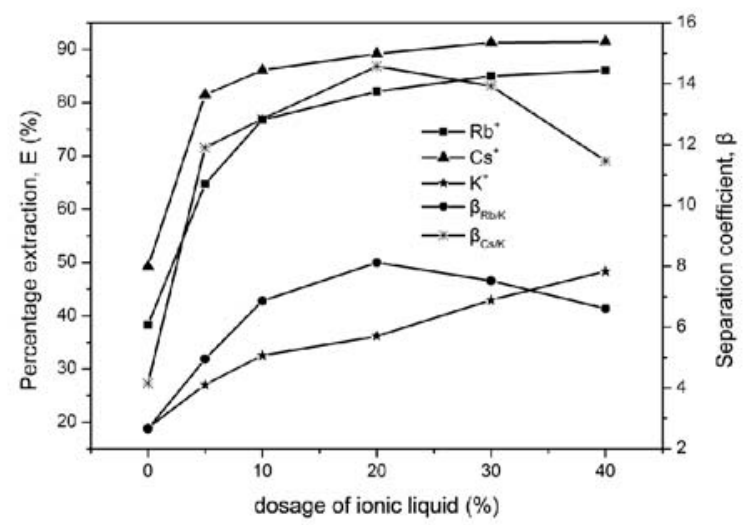

Figure 4. Effects of RTILs Volume in solvent on extraction efficiencies of metal ions (the concentration of $18 \mathrm{C} 6$ is $0.5 \mathrm{~mol} / \mathrm{L}, \mathrm{O} / \mathrm{A}$ at $1: 1$, the equilibration time of 15 min and unadjusted $\mathrm{pH}$ )

\section{Effect of $\mathrm{O} / \mathrm{A}$ phase ratio}

As the results were shown in Figure 5, which the influence of $\mathrm{O} / \mathrm{A}$ phase ratio on extraction of $\mathrm{Rb}^{+}$and $\mathrm{Cs}^{+}$between aqueous phase and the organic phase were studied. The results indicated that the extraction efficiency of $\mathrm{Cs}^{+}, \mathrm{Rb}^{+}$and $\mathrm{K}^{+}$increased with the increasing of the $\mathrm{O} / \mathrm{A}$ phase ratio. When the phase ratios is 1.5 , the extraction yield of $\mathrm{Rb}^{+}$and $\mathrm{Cs}^{+}$reached $84.11 \%, 94.99 \%$, respectively. But with further increase of $\mathrm{O} / \mathrm{A}$ phase ratio, the extraction efficiency of $\mathrm{K}^{+}$increased faster than $\mathrm{Cs}^{+}$ and $\mathrm{Rb}^{+}$, the separation factor of $\beta_{\mathrm{Rb} / \mathrm{K}}$ and $\beta_{\mathrm{Cs} / \mathrm{K}}$ tended to be stable. The reason may be that the probability of collision between organic molecule and alkali ions have been increased with the increase in the $\mathrm{O} / \mathrm{A}$ phase ratio ${ }^{\mathbf{1 2}}$.
Based on the above results, the $\mathrm{O} / \mathrm{A}$ phase ratio of $3: 2$ is used for further studies.

\section{STRIPPING}

The optimal extraction conditions of this system were obtained by a series of conditional experiments and it included the concentration of $18 \mathrm{C} 6$ is $0.5 \mathrm{~mol} / \mathrm{L}, 1,2$-dichloroethane/IL of $8 / 2(\mathrm{v} / \mathrm{v}), \mathrm{O} / \mathrm{A}$ of $3: 2$ and unadjusted $\mathrm{pH}$. The single-stage extraction has been conducted under the optimum conditions and the concentration of metal ions was determined. After one stage extraction, the concentration of $\mathrm{Rb}^{+}, \mathrm{Cs}^{+}$and $\mathrm{K}^{+}$in the organic phase is $85.2 \mathrm{mg} / \mathrm{L}, 108.0 \mathrm{mg} / \mathrm{L}$ and $3.85 \mathrm{~g} / \mathrm{L}$, respectively.

\section{Effect of different stripping agents}

Due to the close binding of the alkali metal ions to the crown ether cavity, it is difficult to elute the alkali metal ions, and a strong acid or ammonium salt is usually used as the stripping agent. The five kinds of substances, hydrochloric acid, sulfuric acid, nitric acid, ammonium chloride and ammonium nitrate, were selected as stripping agents to explore their stripping effect on rubidium, cesium and potassium alkali metal ions. Stripping test results are shown in Figure 6. The results indicated that the stripping rate of ammonium chloride and ammonium nitrate is much higher than that of the three strong acids, and the stripping effect of ammonium nitrate is the best. The probably reason is that the hydrate radius of the ammonium ion is closer to the hydrate radius of the cesium ion, so the elution effect is $\mathrm{Cs}^{+}>\mathrm{Rb}^{+}>\mathrm{K}^{+} .90 .55 \%$ of $\mathrm{Rb}^{+}$and $97.73 \%$ of $\mathrm{Cs}^{+}$is eluted from organic phase with a $3.0 \mathrm{~mol} / \mathrm{L}$ 


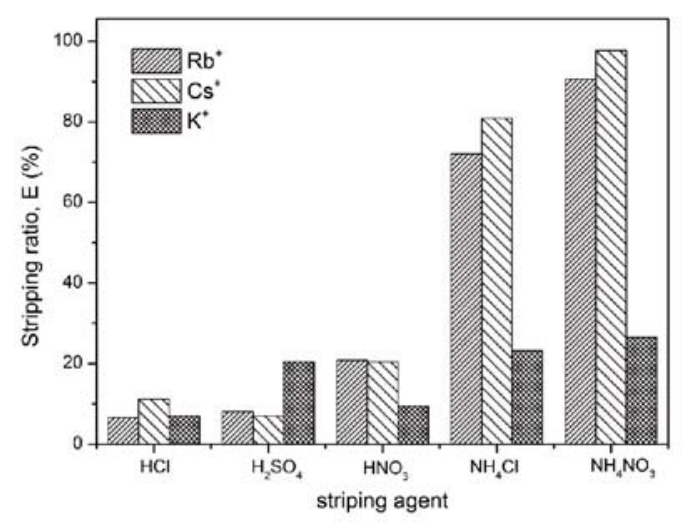

Figure 6. Percentage of stripping of metal ions from the organic phase with different stripping agents (the concentration of stripping agent is $3.0 \mathrm{~mol} / \mathrm{L}, \mathrm{O} / \mathrm{A}$ at $1: 1, \mathrm{~T}=291 \mathrm{~K}$ )

$\mathrm{NH}_{4} \mathrm{NO}_{3}$ solution. Hence, ammonium nitrate is selected as the stripping agent.

\section{Effect of the concentration of stripping agent}

Because the concentration of stripping agent has a great influence on the stripping effect, the stripping effect of different concentrations of ammonium nitrate on metal ions was investigated. As the results shown in Figure 7, we can found that the stripping rate of $\mathrm{Rb}^{+}$ and $\mathrm{Cs}^{+}$increased rapidly when the concentration of ammonium nitrate is $0.1-3.0 \mathrm{~mol} / \mathrm{L}$. When the concentration of ammonium nitrate is higher than $3.0 \mathrm{~mol} / \mathrm{L}$, the stripping rate tend to be stable, but the stripping rate of potassium in the slow increase. When the concentration of ammonium nitrate at $3.0 \mathrm{~mol} / \mathrm{L}$, the stripping rate of $\mathrm{Rb}^{+}, \mathrm{Cs}^{+}$and $\mathrm{K}^{+}$is $90.55 \%, 97.73 \%$ and $26.47 \%$, respectively. The concentration of $\mathrm{Rb}^{+}, \mathrm{Cs}^{+}, \mathrm{K}^{+}$in the aqueous phase after stripped is $77.15 \mathrm{mg} / \mathrm{L}, 105.55 \mathrm{mg} / \mathrm{L}$ and $1.019 \mathrm{~g} / \mathrm{L}$, respectively. The $\mathrm{K} / \mathrm{Cs}$ ratio and $\mathrm{K} / \mathrm{Rb}$ ratio is 9.17 and 11.11 in the aqueous phase, which have dropped $91.21 \%$ and $88.01 \%$ compared with the initial value, respectively. All of this work has taken a big step in the separation and enrichment of $\mathrm{Cs}^{+}\left(\mathrm{Rb}^{+}\right)$and $\mathrm{K}^{+}$. In order to better separate $\mathrm{Cs}^{+}\left(\mathrm{Rb}^{+}\right)$and $\mathrm{K}^{+}, 3.0 \mathrm{~mol} / \mathrm{L}$ ammonium nitrate is selected as the concentration of the stripper.

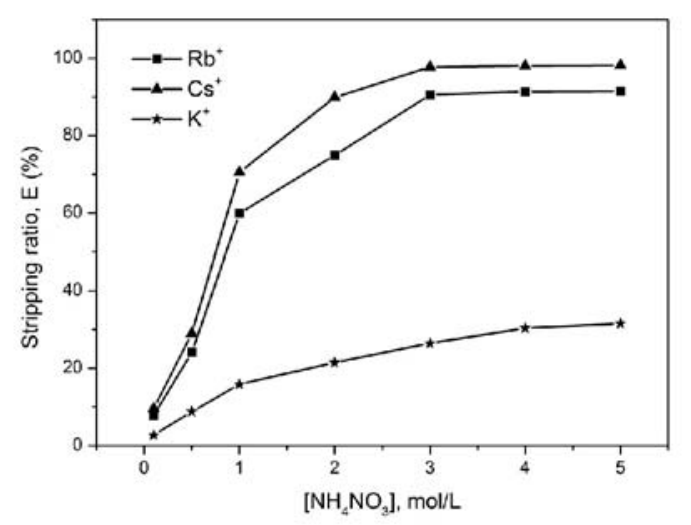

Figure 7. Percentage stripping of metal ions from the organic phase with different concentrations of ammonium nitrate $\left(\mathrm{O} / \mathrm{A}=1: 1, \mathrm{~T}=291 \mathrm{~K},\left[\mathrm{NH}_{4} \mathrm{NO}_{3}\right]=0.1-5.0\right.$ $\mathrm{mol} / \mathrm{L})$

\section{EXTRACTION MECHANISM}

Compared to traditional diluents such as chloroform, the ionic liquid extraction system has a high extraction rate for $\mathrm{Cs}^{+}$and $\mathrm{Rb}^{+}$. Therefore, the mass transfer process of metal ions from aqueous phase to organic phase has different extraction mechanism compared with the traditional diluent extraction system. In the metal ion extraction system, when the traditional organic solvent as a diluent, the extraction mechanism is mostly neutral composite mechanism. That is, metal ions, extractant and some other ions to form a neutral complex into the organic phase. Take DCH18C6 in the n-octanol system extraction of $\mathrm{Sr}^{2+}$ as an example ${ }^{24}$, the mechanism is shown as below:

$\mathrm{Sr}^{2+}{ }_{a q}+\mathrm{DCH} 18 \mathrm{C} 6_{\text {org }}+2 \mathrm{NO}_{3}^{-}$aq $\rightarrow \mathrm{Sr} \cdot \mathrm{DCH} 18 \mathrm{C} 6 \cdot\left(\mathrm{NO}_{3}\right)_{2 o r g}$

Where DCH18C6 represents the extractant of dicyclohexano-18-crown 6-ether. In this work, the mechanism of ionic liquids extraction system was studied.

The extraction efficiency of 18C6 dissolved in ionic liquid with different chain lengths was investigated under the optimum extraction condition and the results were shown in Table 2.

Table 2. Effect of different ionic liquids on $\mathrm{Rb}^{+}$and $\mathrm{Cs}^{+}$ extraction efficiency

\begin{tabular}{|c|c|c|c|}
\hline Ionic liquid & $\begin{array}{c}{\left[\mathrm{C}_{4} \mathrm{mim}\right]} \\
{\left[\mathrm{PF}_{6}\right]}\end{array}$ & $\begin{array}{c}{\left[\mathrm{C}_{6} \mathrm{mim}\right]} \\
{\left[\mathrm{PF}_{6}\right]}\end{array}$ & $\begin{array}{c}{\left[\mathrm{C}_{8} \mathrm{mim}\right]} \\
{\left[\mathrm{PF}_{6}\right]}\end{array}$ \\
\hline $\mathrm{E} \%\left(\mathrm{Rb}^{+}\right)$ & $84.11 \pm 0.74$ & $81.43 \pm 0.82$ & $79.08 \pm 0.75$ \\
\hline $\mathrm{E} \%\left(\mathrm{Cs}^{+}\right)$ & $94.99 \pm 0.68$ & $90.65 \pm 0.91$ & $88.73 \pm 0.88$ \\
\hline
\end{tabular}

The results of Table 2 show that the extraction rate of metal ions increases with decreasing number of carbon atoms in the alkyl chain. The possible reason for this fact is that the hydrophobicity and viscosity of the ionic liquid are enhanced with the increase of its alkyl chain, which adversely affects the mass transfer in the biphasic system. Herein, we considered that the extraction of $\mathrm{Rb}^{+}$and $\mathrm{Cs}^{+}$in $18 \mathrm{C} 6 /\left[\mathrm{C}_{4} \mathrm{mim}\right]\left[\mathrm{PF}_{6}\right]$ system involves a cation-exchange mode. So the expression for the $\mathrm{M}^{+}$ $(\mathrm{M}=\mathrm{Rb}, \mathrm{Cs})$ participation into the organic phase can be presented as:

$M_{\text {aq }}^{+}+c_{4} \mathrm{mim}_{\text {org }}^{+}+n 18 \mathrm{C} 6_{\text {org }} \rightarrow[M \cdot n 18 \mathrm{C6}]_{\text {org }}^{+}+c_{4} \mathrm{mim}^{+}$

To analyze the extraction process of the ionic liquid system, the concentration of $\left[\mathrm{C}_{6} \mathrm{mim}\right]^{+}$in the aqueous phase had been determined by UV absorption before and after the extraction. What's more, the concentration of $\mathrm{Rb}^{+}$and $\mathrm{Cs}^{+}$in the aqueous phase had been determined by atomic absorption spectroscopy. The results were shown in Table 3 and Figure 8.

As is shown above, the exchange of part of the ionic liquid dissolved in the aqueous phase with other metal ions results in a variation of $\left[\mathrm{C}_{4} \mathrm{mim}\right]^{+}$concentration of $8.244 \times 10^{-3} \mathrm{~mol} / \mathrm{L}$. It can be found from Table 3 that the change in the concentration of $\mathrm{Rb}^{+}$and $\mathrm{Cs}^{+}$increased with increase of $\left[\mathrm{C}_{4} \mathrm{mim}\right]^{+}$concentration. The linear relationship between the change in the concentration of $\left[\mathrm{C}_{4} \mathrm{mim}\right]^{+}$and $\mathrm{Rb}^{+}\left(\mathrm{Cs}^{+}\right)$is significant. It is indicated that ionic liquid is directly involved in the extraction process of $\mathrm{Rb}^{+}\left(\mathrm{Cs}^{+}\right)$. This may reveal that the mechanism of this ionic liquid system is cation exchange. In this extraction system, the ionic liquid is not only used as a solvent, 
Table 3. The change of concentrations of $\mathrm{Rb}^{+}, \mathrm{Cs}^{+}$and $\mathrm{C}_{4} \mathrm{mim}^{+}$in the aqueous phase before and after the extraction in the $18 \mathrm{C} 6 /$ $\left[\mathrm{C}_{4} \mathrm{mim}\right][\mathrm{PF} 6]$ system

\begin{tabular}{|c|c|c|c|c|c|c|c|c|}
\hline $\begin{array}{c}{\left[\mathrm{M}^{+}\right]_{\text {initial }} / \mathrm{mg} / \mathrm{L}} \\
(\mathrm{M}=\mathrm{Rb}, \mathrm{Cs})\end{array}$ & 0 & 50 & 100 & 150 & 200 & 250 & 300 & 400 \\
\hline $\begin{array}{c}\Delta\left[\mathrm{Rb}^{+}\right]_{\mathrm{aq}} / \\
10^{-3} \mathrm{~mol} / \mathrm{L}\end{array}$ & 0 & 0.41 & 0.82 & 1.22 & 1.63 & 2.04 & 2.45 & 3.27 \\
\hline $\begin{array}{c}\Delta\left[\mathrm{Cs}^{+}\right]_{\mathrm{aq}} / \\
10^{-3} \mathrm{~mol}_{\mathrm{L}}\end{array}$ & 0 & 0.29 & 0.59 & 0.88 & 1.18 & 1.47 & 1.77 & 2.36 \\
\hline $\begin{array}{c}\Delta\left[\mathrm{C}_{4} \mathrm{mim}^{+}\right]_{\mathrm{aq}} / \\
10^{-3} \mathrm{~mol} / \mathrm{L}\end{array}$ & 8.224 & 8.856 & 9.535 & 10.191 & 10.612 & 11.432 & 11.970 & 13.352 \\
\hline
\end{tabular}

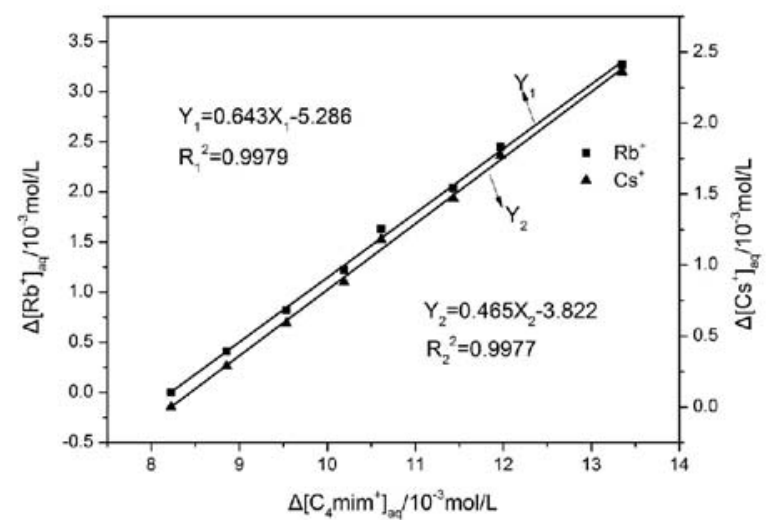

Figure 8. The change of concentrations of $\mathrm{Rb}+, \mathrm{Cs}+$ and $\mathrm{C}_{4} \mathrm{mim}+$ in the aqueous phase before and after the extraction in the $18 \mathrm{C} 6 /\left[\mathrm{C}_{4} \mathrm{mim}\right][\mathrm{PF} 6]$ system

but also as a co-solvent to some extent. So, the ionic liquid may be regarded as a special functional medium.

\section{CONCLUSIONS}

The room temperature ionic liquid, $\left[\mathrm{C}_{4} \mathrm{mim}\right]\left[\mathrm{PF}_{6}\right]$, was successfully used to extract $\mathrm{Rb}^{+}$and $\mathrm{Cs}^{+}$from brine solution which exhibited characteristically high $\mathrm{K}$ to $\mathrm{Rb}$ (Cs) ratios. Optimal extraction conditions of this ionic liquid system have been studied. The single extraction efficiency of $\mathrm{Rb}^{+}$and $\mathrm{Cs}^{+}$was up to $84.11 \%$ and $94.99 \%$, respectively, which was obtained under optimal conditions. Compared with the conventional extraction system, the 18C6 in conjunction with the present ionic liquid provided extraordinary extraction of $\mathrm{Rb}^{+}$and $\mathrm{Cs}^{+}$from the brine solutions. $3 \mathrm{~mol} / \mathrm{L}$ ammonium nitrate on the $\left[\mathrm{C}_{4} \mathrm{mim}\right]\left[\mathrm{PF}_{6}\right] / 18 \mathrm{C} 6$ system has a good stripping effect. Cation exchange was proposed to be the mechanism of extraction followed in ionic liquid. The ionic liquid was not only regarded as the solvent but also the co-extraction reagent to some extent. Preliminary results indicated that the ionic liquids had the potential to replace traditional volatile organic solvents in liquid/ liquid extraction of metal ions.

\section{ACKNOWLEDGMENTS}

The authors appreciate the financial support of National Natural Science Foundation of China (No. 21267018), the Program of Haixi state science and technology bureau enterprise technology innovation project in Qinghai province (No.2016-Q02).

\section{LITERATURE CITED}

1. Arnold, W.D., Crouse, D.J., \& Brown, K.B. (1965). Solvent extraction of cesium (and rubidium) from ore liquors with substituted phenols. Industrial \& Engineering Chemistry Process Design and Development 4(3), 249-254. DOI: 10.1021/ i260015a002.

2. McDowell, W.J., Case, G.N., McDonough, J.A., \& Bartsch, R.A. (1992). Selective extraction of cesium from acidic nitrate solutions with didodecylnaphthalenesulfonic acid synergized with bis (tert-butylbenzo)-21-crown-7. Anal. Chem. 64(23), 3013-3017. DOI: 10.1021/ac00047a024.

3. Tsai, S.C., Wang, T.H., Li, M.H., Wei, Y.Y., \& Teng, S.P. (2009). Cesium adsorption and distribution onto crushed granite under different physicochemical conditions. J. Hazard. Mater. 161(2), 854-861. DOI:10.1016/j.jhazmat.2008.04.044.

4. Li, Z., Pranolo, Y., Zhu, Z., \& Cheng, C.Y. (2017). Solvent extraction of cesium and rubidium from brine solutions using 4-tert-butyl-2-( $\alpha$-methylbenzyl)-phenol. Hydrometallurgy 171, 1-7. DOI: 10.1016/j.hydromet.2017.03.007.

5. Ding, D., Zhao, Y., Yang, S., Shi, W., Zhang, Z., Lei, Z., \& Yang, Y. (2013). Adsorption of cesium from aqueous solution using agricultural residue-Walnut shell: Equilibrium, kinetic and thermodynamic modeling studies. Water Res. 47(7), 2563-2571. DOI: 10.1016/j.watres.2013.02.014.

6. Wang, J., Che, D., \& Qin, W. (2015). Extraction of rubidium by t-BAMBP in cyclohexane. Chinese J. Chem. Eng. 23(7), 1110-1113. DOI: 10.1016/j.cjche.2015.04.005.

7. Yang, W.J., Liu, S. M., Li, Y.J., Huang, Y.J., \& Luo, X.S. (2013). Process analysis of $\mathrm{Rb}^{+}$and $\mathrm{Cs}^{+}$adsorption from salt lake brine by ammonium molybdophosphate composite material. In Advanced Materials Research (Vol. 785, pp. 812-816). Trans Tech Publications. DOI: 10.4028/www.scientific.net/ AMR.785-786.812.

8. Liu, S.M., Liu, H.H., Huang, Y.J., \& Yang, W.J. (2015). Solvent extraction of rubidium and cesium from salt lake brine with t-BAMBP-kerosene solution. T. Nonferr. Metal. Soc. 25(1), 329-334. DOI: 10.1016/S1003-6326(15)63608-1.

9. Ali, S.M., Joshi, J.M., Deb, A.S., Boda, A., Shenoy, K.T., \& Ghosh, S.K. (2014). Dual mode of extraction for $\mathrm{Cs}^{+}$and $\mathrm{Na}^{+}$ions with dicyclohexano-18-crown-6 and bis (2-propyloxy) calix [4] crown-6 in ionic liquids: density functional theoretical investigation. RSC Adv. 4(44), 22911-22925. DOI: 10.1039/ C4RA02246G.

10. Jianchen, W., Xiaowen, Z., \& Chongli, S. (2005). Extracting Performance of Cesium by 25, 27-Bis (2-Propyloxy) Calix [4]-26, 28-Crown-6 (iPr-C[4]C-6) in n-octanol. Sep. Sci. Technol. 40(16), 3381-3392. DOI: 10.1080/01496390500423730

11. Visser, A.E., \& Rogers, R.D. (2003). Room-temperature ionic liquids: new solvents for f-element separations and associated solution chemistry. J. Solid State Chem. 171(1), 109-113. DOI: 10.1016/S0022-4596(02)00193-7.

12. Shi, C., Jia, Y., Zhang, C., Liu, H., \& Jing, Y. (2015). Extraction of lithium from salt lake brine using room temperature ionic liquid in tributyl phosphate. Fusion Eng. Des. 90, 1-6. DOI: 10.1016/j.fusengdes.2014.09.021.

13. Rogers, R.D. (2007). Materials science: reflections on ionic liquids. Nature 447(7147), 917-918. DOI: 10.1038/447917a. 
14. Rout, A., Venkatesan, K.A., Srinivasan, T.G., \& Rao, P.V. (2011). Extraction and third phase formation behavior of $\mathrm{Eu}(\mathrm{III}) \mathrm{IN}$ CMPO-TBP extractants present in room temperature ionic liquid. Sep. Purif. Technol. 76(3), 238-243. DOI: 10.1016/j. seppur.2010.10.009.

15. Han, J., Wang, Y., Chen, C., Kang, W., Liu, Y., Xu, K., \& Ni, L. (2014). (Liquid+ liquid) equilibria and extraction capacity of (imidazolium ionic liquids + potassium tartrate) aqueous two-phase systems. J. Mol. Liq. 193, 23-28. DOI: 10.1016/j.molliq.2013.12.022.

16. Welton, T. (1999). Room-temperature ionic liquids. Solvents for synthesis and catalysis. Chem. Rev. 99(8), 2071-2084. DOI: $10.1021 / \mathrm{cr} 980032 \mathrm{t}$.

17. Pandey, S. (2006). Analytical applications of roomtemperature ionic liquids: A review of recent efforts. Anal. Chim. Acta 556(1), 38-45. DOI: 10.1016/j.aca.2005.06.038.

18. Shi, C., Duan, D., Jia, Y., \& Jing, Y. (2014). A highly efficient solvent system containing ionic liquid in tributyl phosphate for lithium ion extraction. J. Mol. Liq. 200, 191-195. DOI: 10.1016/j.molliq.2014.10.004.

19. Shang-Qing, C.H.E.N., Meng-Xue, W.A. N.G., Long, L.I., Ya-Fei, G.U.O., Xiao-Ping, Y.U., \& Tian-Long, D.E.N.G. (2017). Recovery of Rubidium and Cesium from Brines by Solvent Extraction. DEStech Transactions on Materials Science and Engineering, DOI: 10.12783/dtmse/icmsea/mce2017/10798.

20. Luo, H., Dai, S., Bonnesen, P.V., Buchanan, A.C., Holbrey, J.D., Bridges, N.J., \& Rogers, R.D. (2004). Extraction of cesium ions from aqueous solutions using calix [4] arene-bis (tert-octylbenzo-crown-6) in ionic liquids. Anal. Chem. 76(11), 3078-3083. DOI: 10.1021/ac049949k.

21. Dai, S., Ju, Y.H., \& Barnes, C.E. (1999). Solvent extraction of strontium nitrate by a crown ether using room-temperature ionic liquids. J. Chem. Soc., Dalton Trans. (8), 1201-1202. DOI: 10.1039/A809672D.21/22. Visser, A.E., et al. (2003). Uranyl coordination environment in hydrophobic ionic liquids: an in situ investigation. Inorg. Chem. 42(7), 2197-2199. DOI: 10.1021/ic026302e.

22. Visser, A.E., Jensen, M.P., Laszak, I., Nash, K.L., Choppin, G.R., \& Rogers, R.D. (2003). Uranyl coordination environment in hydrophobic ionic liquids: an in situ investigation. Inorg. Chem. 42(7), 2197-2199. DOI: 10.1021/ic026302e.

23. Zhang, N., Gao, D.L., Liu, M.M., \& Deng, T.L. (2014). Rubidium and Cesium Recovery from Brine Resources. In $A d v$. Mater. Res. (Vol. 1015, pp. 417-420). Trans Tech Publications.

24. Horwitz, E.P., Dietz, M.L., \& Fisher, D.E. (1990). Extraction of strontium from nitric acid solutions using dicyclohexano18-crown-5 and its derivatives. Solvent Extr. Ion Exc. 8(4-5), 557-572. DOI: 10.1080/07366299008918017. 